\title{
Regionalism in Standards: Good or Bad for Trade?*
}

\author{
Maggie Xiaoyang Chen ${ }^{\dagger}$ \\ University of Colorado at Boulder
}

Aaditya Mattoo

World Bank

October 2004

\begin{abstract}
Regional agreements on standards have been largely ignored by economists and unconditionally blessed by multilateral trade rules. We find, theoretically and empirically, that such agreements increase trade between participating countries but not necessarily with the rest of the world. Adopting a common standard in a region, i.e. harmonization, boosts exports of excluded developed countries to the region but reduces exports of excluded developing countries - possibly because developing country firms are hurt more by an increase in the stringency of standards and benefit less from economies of scale in integrated markets. Mutual Recognition Agreements (MRAs) are more uniformly trade promoting unless they contain restrictive rules of origin, in which case intra-regional trade increases at the expense of trade with other, especially developing, countries. We propose a modification of international trade rules to strike a better balance between the interests of integrating and excluded countries.
\end{abstract}

Key words: standard, harmonization, MRA, rules of origin, scale economy

JEL codes: F12, F13, F15

\footnotetext{
${ }^{*}$ The authors have benefited from discussions with Paul Brenton, Carsten Fink, Kishore Gawande, Bernard Hoekman, Murat Iyigun, Jim Markusen, Keith Maskus, Robert McNown, Kamal Saggi, and participants of seminars at the World Bank, US International Trade Commission (ITC), and University of Colorado at Boulder. The views expressed here are those of the authors and should not be attributed to the World Bank.

${ }^{\dagger}$ Department of Economics, University of Colorado at Boulder, Boulder, CO 80309; Phone: (303) 859-1853; Email: xiaoyang.chen@colorado.edu.

${ }^{\ddagger}$ Development Research Group, World Bank, 1818 H Street, NW, Washington, DC 20433; Phone: (202) 458-7611; Email: amattoo@worldbank.org.
} 


\section{Introduction}

In their recently launched trade talks, the European Union and the Association of Southeast Asian Nations (ASEAN) agreed to focus not on tariffs and quotas but on what Pascal Lamy, the EU trade commissioner, called "the real 21st century trade issues": harmonizing standards. ${ }^{1}$ This is the latest episode in a process of deep integration that is most advanced within the European Union but also underway in many other regions. Two factors explain the shift in regional negotiating emphasis away from conventional barriers and toward standards. First, multilateral negotiations have achieved remarkable reductions in tariffs and quotas but done relatively little to reduce the trade restrictive impact of technical barriers. Second, while multilateral trade rules governing regional agreements on tariffs seek at least in principle to balance the interests of integrating countries and the rights of excluded countries, ${ }^{2}$ the rules treat regional agreements on standards as always benign and worthy of encouragement. ${ }^{3}$

Are regional agreements on technical barriers indeed an unambiguous blessing for global trade? The voluminous research on regionalism with its almost exclusive focus on tariffs and quotas provides no adequate answer. This paper is a first step in the theoretical and empirical analysis of regional initiatives on technical barriers to trade. Using a simple analytical model, it asks: How must the conventional analysis of free trade areas and customs unions be modified to apply to agreements on standards? And what elements of international agreements on standards are relevant to predicting their impact on patterns of trade? Then employing a specially constructed panel dataset that directly identifies different types of policy initiatives in each manufacturing industry, the paper addresses two empirical questions: Do regional agreements on standards lead to significant increase

\footnotetext{
${ }^{1}$ The two groups of countries have ageed to begin by harmonizing sanitary standards in the agricultural and fisheries sector, as well as technical standards for electronics and wood-based industries. Pascal Lamy, the EU trade commissioner said that the choice was driven by the belief that "the real 21st century trade issues were standards and rules in areas such as safety, health or consumer protection", rather than tarriffs or quotas ("EU and Asean to pave way for trade pact talks", Financial Times, 7 September 2004.)

${ }^{2}$ These rules are in Article XXIV of GATT 1994.

${ }^{3}$ Article 2.7 of the WTO's Agreement on Technical Barriers to Trade encourages members to "give positive consideration to accepting as equivalent technical regulations of other members, provided they are satisfied that these regulations adequately fulfill the objectives of their own regulations." This provision would seem to allow a country to selectively recognize standards of other countries, without violating the fundamental obligation not to discriminate between its trading partners. There is no mention of the rights of, or obligations vis-à-vis, countries that happen not to receive "positive consideration."
} 
in trade between participating countries? And what happens to trade with those that are left out?

Agreements on standards raise issues that are both politically and analytically challenging. Unlike tariffs, standards cannot be simply negotiated away because the original reason for their existence is not trade protection but the enhancement of welfare by remedying market failure - arising, for example, from invisible safety attributes of products, negative environmental externalities, or product incompatibility due to the producers' failure to coordinate. Agreements on standards must therefore secure the gains from integrated markets without unduly compromising the role of standards as remedies for market failure. Not only are the motives for standards ostensibly honorable, so in principle is their implementation: unlike tariffs, the same standards are imposed on both foreign and domestic firms. However, in spite of the supposed symmetry of treatment, the impact on trade may turn out highly asymmetric because the costs of compliance are likely to differ across countries.

There are in fact three main types of agreements dealing with technical barriers to trade. The simplest, and potentially most powerful is the mutual recognition of existing standards, whereby a country grants unrestricted access of its market to products that meet any participating country's standards. This was the approach taken in principle by the European Union, with the spur of the Cassis de Dijon judgement of the European Court of Justice. Mutual recognition agreements (MRAs) are, however, not likely to be an option if there is a significant difference in the initial standards of the countries, as became evident in the context of the European Union. ${ }^{4}$

In such cases, a certain degree of harmonization is a precondition for countries to allow products of other countries to access their markets. The most important example of such harmonization is the New Approach of the European Union, which resulted in a set of directives from the European Commission setting out essential health and safety re-

\footnotetext{
${ }^{4}$ The central problem in the EU mutual recognition approach is the overarching exemption contained in Article 36 of the EC treaty. This provision preserves the member countries' rights to restrict or prohibit imports on grounds of health and safety and other policy objectives, as long as this is not "a means of arbitrary discrimination or a disguised restriction on trade". This provision substantially dilutes the effects of implementing mutual recognition because it allows a country with stringent regulations not to recognize as equivalent the regulations of other countries with lower stringency.
} 
quirements for most regulated products. ${ }^{5}$ Available evidence suggests that harmonization within the EU tended toward the high range of initial standards. Vogel (1995) points out that the role of the Union's richest and most powerful members, which imposed the most stringent standards, has been critical in setting the EU standards agenda; their political and economic importance has served to make EU standards progressively stricter. ${ }^{6}$

In many other cases, neither mutual recognition nor harmonization of substantive standards may be deemed feasible or desirable. Countries may nevertheless choose at least to mutually recognize each other's conformity assessment requirements, i.e. country A trusts country B to certify that the products made by country B conform to country A's standards. Examples of such initiatives are the intra-EU MRAs on some unharmonized industries and the EU's agreements with a number of other countries. A key element of these agreements is the rule of origin. ${ }^{7}$ The MRAs between the EU and USA and the EU and Canada specify that conformity assessment done in one of the MRA countries, in which products are manufactured or through which they are imported, is accepted throughout the entire agreement region. Other agreements, such as the MRAs the EU has concluded with Australia and New Zealand, impose restrictive rules of origin which require that third country products continue to meet the conformity assessment of each country in the region.

As a prelude to our empirical investigation of the effects of these agreements on trade patterns, a simple analytical model is used to generate certain testable hypotheses. The main analytical results can be explained by drawing a partial analogy between standards harmonization and mutual recognition, on the one hand, and a customs union and a free trade area, on the other. As in the case of a customs union, the economic impact of stan-

\footnotetext{
${ }^{5}$ In practice, most of the broad manufacturing product areas where technical regulations are important have now been harmonized, particularly product areas where the mutual recognition approach was seen to be failing.

${ }^{6}$ EC (1998) Single Market Review concludes that the harmonized standards in most reviewed industries have been set higher than initial levels in most member countries. The history of EU automobile emission, chemical, and packaging standards also demonstrates that these standards have frequently been harmonized at a level slightly lower than that preferred by the Union's most stringent states, including Germany, Denmark, and Netherlands, but higher than favored by less strict members such as Italy, UK, and Spain (Vogel, 1995).

7 "Rules of origin" are defined by the WTO as "the criteria used to define where a product was made. They are an essential part of trade rules because a number of policies (such as preferential trade agreements) discriminate between exporting countries."
} 
dards harmonization depends on the level at which the harmonized standard is set. Unlike the case of a customs union, standards harmonization has a market integration effect that creates scale economy benefits for the firms of not just participating but also third countries. The impact on the firms of a specific country depends on how the costs of meeting the new harmonized level of the standard compare with the benefits from economies of scale in integrated markets. We find that if firms from one set of countries ("developing") have a higher variable cost of meeting a standard and reap fewer scale economy benefits in integrated markets than firms from another set of countries ("developed"), then the former can suffer a decline in exports to the integrated market when harmonization raises some destination countries' standards.

As in the case of a free trade area, the economic impact of a standards MRA depends critically on the choice of rules of origin. For the participating countries, an MRA is in effect a downward harmonization of standards since firms are now free to meet the least costly of the initial standards: trade is stimulated not only by market integration but also by the reduced stringency of the standard. The analytical implications for imports from third countries differ dramatically with rules of origin. If firms of third countries are denied the benefits of the MRA and must continue to meet the original standard in each market, then they will face unchanged absolute conditions but suffer a decline in relative competitiveness - and hence a decline in exports to the region. In contrast, if the firms of non-participating countries are also entitled to access the entire region by conforming to the least costly standard, then they too reap benefits. In this case, it is shown that firms from the set of countries ("developing") where it is more costly to meet a standard may benefit more, because there is a greater reduction in their compliance costs thanks to the decline in the stringency of the standard.

In order to test the empirical validity of these propositions, we construct the first dataset that directly identifies policy initiatives of different types on standards for manufacturing industries in 42 countries over the period of 1986-2001. ${ }^{8}$ These include all OECD countries and 14 developing countries that are the largest exporters of manufactured goods outside the OECD and account for over $80 \%$ of non-OECD manufactured exports. The

\footnotetext{
${ }^{8}$ In contrast, the existing Perinorm dataset describes standards and technical regulations, but does not allow an unambiguous measurement of harmonization or mutual recognition.
} 
policy measures include each harmonization directive and MRA concluded between the countries in the set. We concord the policy measures, which often pertain to a specific attribute (e.g. safety) of a variety of products, with trade data at the SITC (revision 2) 3-digit industry level. We then estimate the significance of the impacts of these measures on bilateral trade across countries and over time, controlling for other influences.

Our evidence broadly confirms the conclusions drawn from the model. Regional harmonization significantly increases intra-regional trade in affected industries. Exports to the region of excluded developed countries also increase, but exports of excluded developing countries decline. These asymmetric effects may arise because developing country firms are hurt more by an increase in the stringency of standards and benefit less from economies of scale in integrated markets. Mutual Recognition Agreements (MRAs) promote trade both within the region and with the rest of the world. But when they contain restrictive rules of origin, then intra-regional trade increases at the expense of trade with other, especially developing, countries.

To place our contribution in the context of the existing literature,$^{9}$ the analytical section builds on the work of Baldwin (2000) and Ganslandt and Markusen (2001). In particular, Baldwin (2000) anticipated some of the results of this paper on MRAs, but assumed identical countries with identical fixed costs of complying with standards. So the implications of harmonization and asymmetric effects on excluded countries were beyond the scope of that model. As far as we know, only two previous studies have empirically explored the impact of shared standards on trade. Swann et al (1996) regressed British net exports, exports and imports over the period 1985-1991 on counts of voluntary national ("idiosyncratic") and international standards recognized by the United Kingdom and Germany. They discovered that international standards to which Britain was a party had little impact on imports but a significantly positive effect on exports while British national standards tended to raise both imports and exports. Moenius (1999) regressed bilateral trade volumes in 4-digit SITC sectors on counts of shared standards in a sample of 14 countries over 16 years, and found a positive and highly significant relationship. Our paper differs from these empirical contributions in a number of aspects. First, instead

\footnotetext{
${ }^{9}$ See Maskus and Wilson (2001) for a review of the literature.
} 
of relying on approximate measures of shared standards, we directly identify harmonization directives and mutual recognition initiatives in specific industries across countries, and also distinguish between the impacts of these two types of measures. Second, we examine not only the effect on trade between participating countries, but also on trade with excluded countries. Finally, we allow for differing impacts of harmonization across destination markets, depending on whether they previously had more or less stringent standards, and across source countries, depending on the level of development.

The rest of this paper is organized as follows. In Section 2, we present the analytical model and identify the main implications for trade of different types of initiatives. We discuss the data in Section 3, and present the empirical evidence in Section 4. In Section 5 , we examine the robustness of our estimates. Section 6 concludes the paper and draws out the implications for the design of international trade rules.

\section{Model}

We construct a model that enables us to capture the essence of regional initiatives on standards while allowing affected countries to be heterogeneous. Each country imposes a mandatory standard $s_{j}$, which a firm must meet in order to sell its goods to the country's consumers. ${ }^{10}$ To keep the model fairly general, we do not specify a particular rationale for the standard. However, to motivate the analysis, it is convenient to think of a safety standard which pertains to a product attribute (e.g. inflammability) that cannot be independently observed by consumers. ${ }^{11}$ But the assurance that a particular product meets a higher standard has a positive impact on consumer demand for the product and thus a firm's revenue. ${ }^{12}$

Compliance with the standard is assumed to affect both the marginal and fixed costs

\footnotetext{
${ }^{10}$ We take $s_{j}$ as given in this paper, even though the level of $s_{j}$ in each country could be treated as endogenously determined, based on factors such as preferences, market size, income, and technology. Allowing standards to be optimally set, prior to and after harmonization, would significantly complicate the analysis without providing much additional insight into the issues addressed here.

${ }^{11}$ Most EU harmonization directives have set out essential requirements that are targeted at the safety of the product user and protecting the user's health (from infection, toxins, explosion, cuts or wounds from mechnical parts, electric shock, burning, falls, etc.).

${ }^{12}$ One exception in the EU New Approach is the "Packaging and Packaging Waste Directive". This directive aims at reducing a negative consumption externality, such as pollution, and thus does not cause shift in consumer demand. However, our findings also apply to this type of standard.
} 
of firms. We assume that the marginal cost of production is identical for all firms in a particular country $i$ and proportional to the level of the standard in the destination market $j, s_{j}$, i.e. $c_{i}\left(s_{j}\right) \equiv c_{i} s_{j}$. Furthermore, a firm (denoted by $a$ ) in country $i$ must incur a fixed cost of production, denoted by $F_{i}^{a}$, to meet each distinct standard in the destination markets to which it sells. There is a continuum of $\bar{n}$ potential firms in each country $i$ with their fixed cost, $F_{i}^{a}$, uniformly distributed between $F_{i}$ and $F_{i}+\Delta F$, i.e. $F_{i}^{a} \sim \operatorname{UNIF}\left[F_{i}, F_{i}+\Delta F\right] .{ }^{13} F_{i}^{a}$ is assumed to be independent of the level of the standard in the destination market, $s_{j}$.

First, we consider the firms' behavior. We assume that firms treat markets with different standards as segmented, i.e. a firm will not find it worthwhile to supply multiple markets by complying with the most stringent standard. ${ }^{14}$ In contrast, firms treat markets with the same standard as a single market when making entry decisions and subsequently competing in quantities. Solving backwards, a representative firm (firm $a$ ) that is located in country $i$ and sells in all markets with the same standard at $s_{j}$, chooses its output $q_{i j}$ to solve the following profit-maximization problem:

$$
\max _{q_{i j}} \sum_{j} \pi_{i j}^{a}=\sum_{j} R_{i j}\left(s_{j}, \sum_{z} q_{z j}, q_{i j}\right)-\sum_{j} c_{i} s_{j} q_{i j}-F_{i}^{a}
$$

where $j$ represents any market that sets the standard at $s_{j}$, and $R_{i j}$ denotes the revenue that is a function of $s_{i}$. Note that firms only need to incur a single fixed cost to serve all the markets with the standard set at $s_{j}$. The first-order condition is:

$$
\frac{\partial R_{i j}\left(s_{j}, \sum_{z} q_{z j}, q_{i j}\right)}{\partial q_{i j}}-c_{i} s_{j}=0
$$

which yields the profit-maximizing reaction function, i.e. $q_{i j}=q_{i j}\left(q_{z j}\right)$ where $z \neq i$. By solving all reaction functions simultaneously, we find $q_{i j}^{*}$ for each $i$ as a function of $n_{z j}(\forall z)$,

\footnotetext{
${ }^{13}$ Alternatively, we could have assumed that firms in each country $i$ must incur identical fixed costs. The assumption in the text simplifies the analysis with little loss of generality.

${ }^{14}$ In other words, the difference in total variable costs of complying with any two standards is larger than any saving in fixed costs from meeting just the stricter one. Our assumption also holds when the issue is not vertical differentiation of products on some quality dimension, but the incompatibility of products that conform to different standards (e.g. two-prong versus three-prong plugs).
} 
the number of firms from country $z$ selling in market $j$. Denote $V_{i j}^{*}=R_{i j}\left(s_{j}, \sum_{z} q_{z j}^{*}, q_{i j}^{*}\right)-$ $c_{i} s_{j} q_{i j}^{*}$ as the revenue less the variable cost realized in market $j$ at the profit maximum.

Suppose $N_{j}$ number of markets set the same standard as country $j .{ }^{15}$ A firm would choose to enter these $N_{j}$ markets simultaneously only if the nonnegative total profit condition holds: $\sum_{j} \pi_{i j}^{a}=N_{j} V_{i j}^{*}-F_{i}^{a} \geqslant 0$.

Next consider importing country markets. The number of firms from country $i$ that supply each of these $N_{j}$ markets, denoted by $n_{i j}$, can be found by solving the following equation:

$$
n_{i j}=\bar{n} \cdot \frac{N_{j} V_{i j}^{*}-F_{i}}{\Delta F}
$$

because, in each country $i$, there is a continuum of $\bar{n}$ firms with their fixed cost uniformly distributed between $F_{i}$ and $F_{i}+\Delta F$. Rewriting the above equation, we get $n_{i j}$ as a reaction function of the number of rival firms from every other country $z(z \neq i)$, i.e. $n_{i j}=n_{i j}\left(n_{z j}\right)$. Solving the reaction functions simultaneously for all $j$, we obtain the equilibrium number of firms in any market $j$ from each source country, i.e. $n_{i j}^{*}$. Hence, the total imports of market $j$ from country $i$ is given by $Q_{i j}=n_{i j}^{*} q_{i j}^{*}$.

The goal of our model is to analyze the impact on bilateral trade of a policy initiative that deals with standards. For this purpose, we first characterize the impact on the imports of market $j$ from country $i$ by totally differentiating $Q_{i j}$ :

$$
d Q_{i j}=n_{i j}^{*} d q_{i j}^{*}+q_{i j}^{*} d n_{i j}^{*}+\sum_{z}\left(\frac{\partial q_{i j}^{*}}{\partial n_{z j}} \cdot n_{i j}^{*} \cdot d n_{z j}^{*}\right)
$$

On the right hand side of the above equation, the first argument shows the direct effect on $Q_{i j}$ of a change in the individual firm's output; the second argument represents the direct effect on $Q_{i j}$ of a change in the number of firms from country $i$; the third argument reflects the indirect effect of a change in the number of firms from each source country through its influence on an individual firm's output.

Let's take a closer look at the elements of equation (4). First of all, a change in the

\footnotetext{
${ }^{15}$ In this model, we assume that destinations markets only differ in the level of the standard.
} 
level of the standard has a direct impact on an individual firm's output, indicated by:

$$
d q_{i j}^{*}=\left(\partial q_{i j}^{*} / \partial s_{j}\right) d s_{j}
$$

Furthermore, based on equation (3), both $N_{j}$ and $s_{j}$ determine the number of firms from each source country supplying market $j$. Thus, at equilibrium, $d n_{i j}^{*}$ can be defined as:

$$
d n_{i j}^{*}=\sum_{z}\left[\frac{\partial n_{i j}}{\partial n_{z j}} \cdot d n_{z j}\right]=\sum_{z}\left[\frac{\partial n_{i j}}{\partial n_{z j}} \cdot \frac{1}{\gamma_{z j}}\left(V_{z j}^{*} \cdot d N_{j}+N_{j} \cdot \frac{\partial V_{z j}^{*}}{\partial s_{j}} \cdot d s_{j}\right)\right]
$$

where $\gamma_{i j} \equiv-N_{i}\left(\partial V_{i j}^{*} / \partial n_{i j}\right)+\Delta F / \bar{n}>0$. Note that in this paper we assume $c_{i}>$ $\max \left\{\partial R_{i j}^{*} / \partial s_{j}, \underline{c}\right\}$, which indicates $\partial V_{i j}^{*} / \partial s_{j}, \partial Q_{i j} / \partial s_{j}<0$, i.e. firms would not voluntarily produce a quality that exceeds the level of the standard when the standard pertains to some unobserved attribute of a product. ${ }^{16}$

Taking into account equations (5) and (6), equation (4) can be rewritten as:

$$
\begin{aligned}
d Q_{i j}= & \frac{1}{\gamma_{i j}} \sum_{z}\left[\phi_{i j} \sum_{m}\left(\frac{\partial n_{z j}}{\partial n_{m j}} V_{m j}^{*}\right)+\vartheta_{i j} V_{m j}^{*}\right] d N_{j}+ \\
& {\left[\frac{N_{j}}{\gamma_{i j}}\left[\phi_{i j} \sum_{m}\left(\frac{\partial n_{z j}}{\partial n_{m j}} \frac{\partial V_{m j}^{*}}{\partial s_{j}}\right)+\vartheta_{i j} \frac{\partial V_{z j}^{*}}{\partial s_{j}}\right]+\frac{\partial q_{i j}^{*}}{\partial s_{j}} n_{i j}\right] d s_{j}, }
\end{aligned}
$$

where $\phi_{i j} \equiv n_{i j}\left(\partial q_{i j}^{*} / \partial n_{i z}\right)$ and $\vartheta_{i j} \equiv q_{i j}^{*}\left(\partial n_{i j} / \partial n_{i z}\right)$.

The impact on imports of country $j$ from $i$ of any policy initiative that deals with standards is made up of two elements: the effect of market integration $\left(d N_{j}\right)$ and the effect of change in the standard $\left(d s_{j}\right)$. The first argument on the right-hand-side of equation (7) captures the aggregate impact of market integration on imports through a change in the number of supplying firms. When $d N_{j}>0$, there is an increase in the number of destination markets served by incurring a single fixed cost, which promotes economies of scale and thus spurs market entry. The second argument reflects the direct and indirect

\footnotetext{
${ }^{16} \underline{c}$ is defined in Appendix B.1. This assumption is in alignment with Akerlof (1970), who finds that, in the presence of information asymmetry in qualities, all firms would produce the lowest quality possible at equilibrium. When a positive level of standard is adopted to partially correct the market failure, firms are forced to meet the standard.
} 
effects of a change in the level of the standard, respectively, on the number of firms and firms' output. Assessing the relative strengths of these two effects helps us determine the overall impact on imports of any regional initiatives that deal with standards.

We are particularly interested in exploring the possible asymmetric effects of regional agreements on standards in a heterogeneous world. We assume that the world consists of two types of countries: type $K$ and type $L$, which differ in terms of their firms' costs of complying with standards, i.e. $c_{i}$ and $F_{i}$. Two broad cases are possible: $(i) c_{K}<c_{L}$ and $F_{K}>F_{L}$ or $(i i) c_{K}<c_{L}$ and $F_{K} \leqslant F_{L}$. Our analysis focuses on case $(i)$ for several reasons. First of all, case $(i)$ is more analytically challenging, and once the implications in this case are established, those in case (ii) can be worked out quite straightforwardly. More importantly, case $(i)$ may more accurately depict situations where firms from both rich and poor countries produce the same product. It is likely that firms from richer capital-abundant countries (type $K$ ) tend to adopt a more capital-intensive technology that requires a relatively large $F_{i}$, while firms from poorer labor-abundant countries (type $L)$ tend to adopt a more labor-intensive technology that requires a relatively large $c_{i}$. In fact, the World Bank's (2004) Technical Barriers to Trade Survey reveals that a firm's percentage of compliance cost spent on product re-design for each export market (corresponding to $F_{i}$ in our paper) is positively correlated with the GDP per capita of the country in which it is located, whereas that spent on hiring additional labor for production and testing (corresponding to $c_{i}$ in our paper) is negatively correlated with the GDP per capita of the country. This limited evidence does not, however, provide the basis for an a priori assertion that type $K$ countries correspond to developed countries and type $L$ to developing countries. Rather, we treat this correspondence as a hypothesis to be tested in the empirical section.

In the rest of this section, we examine the impact on both intra-regional trade and trade with excluded countries of two types of regional initiatives: upward harmonization and downward harmonization (with or without rules of origin). 


\subsection{Upward harmonization}

We begin by investigating the impact on trade when a subset of type $K$ countries, denoted by $H \equiv\{h\}$, harmonize their standards at the level of the initially most stringent standards, $\max \left\{s_{j}: j \in H\right\}$. The objective of such an approach, reflecting roughly the EU's directives in the 1990s, would be to integrate markets without compromising the role of the standard as a remedy for market failures in any country.

First, we look at the set of countries within $H$ for which $d s_{j}=0$, i.e. the countries in the harmonizing region with the most stringent initial standards. The impact on firms selling in these markets is solely due to the market integration effect (i.e. the increase in $N_{j}$ ). All exporters to these markets reap economies of scale since they now serve the entire region incurring one single fixed cost. But such market integration benefits are greater for firms of type $K$ countries, since $F_{k}>F_{l}$ and they enjoy a larger reduction in the per-market fixed cost. So we shall certainly see increased entry of firms and imports from type $K$ countries. However, for firms of type $L$ countries, the direct benefits from increased economies of scale are counteracted by the more intense competition from firms of type $K$ countries. Nevertheless, imports from type $L$ countries may still increase if the former effect is not completely offset by the latter.

Next we look at the set of countries within $H$ for which $d s_{j}>0$, i.e. the countries with initial standards less stringent than the eventual harmonized level. Intuitively, the benefit to firms of increased scale economies may be partially or even completely eroded by the increased cost of complying with stricter standards. Provided the initial distance between standards, and hence the upward adjustment of standards, is below a certain threshold value, the imports of harmonizing markets from type $K$ countries will increase. However, imports from type $L$ countries are more likely to decrease because the direct benefits of economies of scale are now counteracted by two factors: type $L$ firms realize smaller economies of scale (because they have lower fixed costs than type $K$ firms ), and are hurt more by the increase in the level of the standard (because they have higher variable costs of meeting a standard). Whether the imports from type $L$ countries actually decline depends on the extent of their cost disadvantage.

The overall impacts on imports of harmonizing countries are summarized below: 
Proposition 1 When region $H$ harmonizes standards at $\max \left\{s_{j}: j \in H\right\}$,

(i) imports of harmonizing markets with $d s_{j}=0$ from type $K$ countries increase, whereas those from type $L$ countries increase if $c_{l}<\bar{g}\left(c_{k}\right)$;

(ii) imports of harmonizing markets with $d s_{j}>0$ from type $K$ countries increase if $d s_{j}<\Delta \bar{s}$, whereas those from type $L$ countries decrease if $c_{l}>\underline{g}\left(c_{k}\right)$.

Proof. See Appendix B.1.

Moreover, we compare the impacts of upward harmonization across destination markets and find:

Proposition 2 The increase in imports of harmonizing market $j$, i.e. $d Q_{i j}$, from any exporter $i$ is a strictly decreasing function of $d s_{j}$.

Proof. See Appendix B.2.

The intuition is obvious: the higher $d s_{j}$, the more the scale economy boost to imports is diluted by the higher costs of compliance with standards.

\subsection{Downward harmonization (mutual recognition)}

Consider now the impact on trade when the countries of region $H$ decide to mutually recognize (MR) one another's standards. In other words, products that comply with a standard set by any participating country can be freely sold in the entire region. It is straightforward to establish that such mutual recognition is equivalent in effect to the downward harmonizing of standards at the level of $\min \left\{s_{j}: j \in H\right\}$, since firms are free to comply with the least strict standard in the region.

The impact on trade with third countries turns out to depend on whether the benefits of MR are extended to third country firms. When the benefits of mutual recognition are restricted to firms within region $H$, the markets of individual countries in this region remain segmented, with the same initial standards, to firms outside the region. Although the absolute conditions of access remain unchanged, firms of excluded countries face a decline in relative competitiveness because firms of participating countries not only realize 
greater economies of scale but also may enjoy reduced stringency of standards. The implications of such mutual recognition differ sharply for firms within the region from those in excluded countries, as summarized below:

Proposition 3 When region $H$ harmonizes standards at $\min \left\{s_{j}: j \in H\right\}$ and imposes restrictive rules of origin, then

(i) intra-regional trade increases at the expense of imports from the rest of world;

(ii) in the rest of the world, type $L$ countries see a larger decline in their exports to region $H$ if $c_{l}>g_{1}\left(c_{k}\right)$.

Proof. See Appendix B.3.

In contrast, when the benefits of mutual recognition are open to all firms, the results in certain respects mirror those presented in Proposition 1. As in the case of upward harmonization, all firms reap the benefits of increased economies of scale due to market integration. But there is now an additional benefit arising from the downward adjustment of the standard in certain countries. Although both of these effects may encourage entry and boost total trade, they are asymmetrically distributed between exporter countries. Type $K$ firms with larger fixed costs tend to benefit more from scale economies whereas type $L$ firms with a higher variable cost of compliance derive greater benefits from reduced stringency of the standard. When there is a significant downward adjustment of the standard, the rise in exports of countries of type $L$ may be greater than that of type $K$.

Proposition 4 If region $H$ harmonizes standards at $\min \left\{s_{j}: j \in H\right\}$ and does not impose restrictive rules of origin, then

(i) imports of region $H$ from type $K$ countries - both within the region and in the rest of the world - increase, whereas those from type $L$ countries increase if $c_{l}<\bar{g}\left(c_{k}\right)$;

(ii) the increase in the total imports of region $H$ from excluded type $L$ countries is greater than that of excluded type $K$ countries if $c_{l}>g_{2}\left(c_{k}\right)$ and $\sum_{H} d s_{j}<\Delta \underline{s}$.

Proof. See Appendix B.4. 


\section{Data}

We employ a balanced dataset, from COMTRADE, covering the trade of 42 countries at the SITC rev. 2 3-digit level of manufacturing industries from 1986 to 2001. The sample consists of 28 OECD countries and 14 developing countries that are the largest manufacturing exporters outside the OECD (and have complete sectoral import data). ${ }^{17}$ Inevitably, there exist some null observations since not all countries trade in each industry every year, and so it is appropriate to use the Tobit model for estimation.

We identify the industries, countries and the time period that are affected by each directive or MRA drawing upon the relevant official documents, and then construct the variables displayed in Table 1. The harmonization directives and MRAs are not directly related to specific products but to product attributes. ${ }^{18}$ Thus a single industry (e.g. electronic products) may be affected by multiple directives (e.g. those pertaining, respectively, to low voltage equipment and electromagnetic compatibility). Different approaches can be taken to quantify the harmonization measures, depending on how these measures are believed to affect trade. It is simplest, and seems reasonable, to assume that the impact is linearly related to the number of directives in each industry, i.e. each additional directive in any industry has an identical incremental affect on trade. Alternative assumptions are possible, e.g. that additional directives have a diminishing effect on trade, or that the nature of the impact differs in each industry. We established that the results are not sensitive to the choice of approach.

$H A R_{i j r t}$ counts the number of directives applicable to industry $r$ between exporter $i$ and importer $j$ in year $t$. $H A R_{-} M_{i j r t}$ counts the number of directives applicable to industry $r$ between importer $j$ and any country other than exporter $i$ in year $t$. For instance, $H A R_{-} M_{i j r t}=1$ for imports of United Kingdom from China in the sector of machinery tools since 1995, because the United Kingdom has implemented a single directive applicable to machinery tools along with other EU members at the end of 1994. HAR_E $E_{i j r t}$ measures the number of directives implemented in industry $r$ between exporter $i$ and any country other than importer $j$ in year $t$.

\footnotetext{
${ }^{17}$ Czech Republic and Slovak Republic are excluded because of the lack of sectoral trade data in 1993 while Belgium and Luxembourg are considered as one unit throughout the period.

${ }^{18}$ The lists of EU directives and MRAs are provided Table A.1 and Table A.2 in Appendix A.
} 
Table 1: Notations in estimation

\begin{tabular}{|c|c|}
\hline \multicolumn{2}{|l|}{ Regressand } \\
\hline $\ln \left(\right.$ import $\left._{i j r t}\right)$ & $\begin{array}{l}\text { the natural logarithm of the imports of country } \mathrm{j} \text { from country } \\
\mathrm{i} \text { in industry } \mathrm{r} \text { and year } \mathrm{t}\end{array}$ \\
\hline \multicolumn{2}{|l|}{ Fixed effects } \\
\hline$\delta_{\text {irt }}$ & exporter-industry-year \\
\hline$\eta_{\text {jrt }}$ & importer-industry-year \\
\hline$\gamma_{i j r}$ & exporter-importer-industry \\
\hline \multicolumn{2}{|l|}{ Regressors } \\
\hline $\mathrm{HAR}_{i j r t}$ & $\begin{array}{l}\text { the number of harmonization directives between } \mathrm{i} \text { and } \mathrm{j} \text { in } \\
\text { industry } \mathrm{r} \text { and year } \mathrm{t}\end{array}$ \\
\hline $\mathrm{HAR} \_\mathrm{M}_{i j r t}$ & $\begin{array}{l}\text { the number of harmonization directives between } \mathrm{j} \text { and any } \\
\text { country other than } \mathrm{i} \text { in industry } \mathrm{r} \text { and year } \mathrm{t}\end{array}$ \\
\hline $\mathrm{HAR} \_\mathrm{E}_{i j r t}$ & $\begin{array}{l}\text { the number of harmonization directives between } \mathrm{i} \text { and any } \\
\text { country other than } \mathrm{j} \text { in industry } \mathrm{r} \text { and year } \mathrm{t}\end{array}$ \\
\hline MRA_RO $\mathrm{RO}_{i j r t}$ & $\begin{array}{l}1 \text { if an MRA with rules of origin exists between } i \text { and } j \text { in } \\
\text { industry } r \text { and year } t \text {, and } 0 \text { otherwise }\end{array}$ \\
\hline $\mathrm{MRA}_{-} \mathrm{RO}_{-} \mathrm{M}_{i j r t}$ & $\begin{array}{l}1 \text { if an MRA with rules of origin exists between } \mathrm{j} \text { and any } \\
\text { country other than } \mathrm{i} \text { in industry } \mathrm{r} \text { and year } \mathrm{t} \text {, and } 0 \text { otherwise }\end{array}$ \\
\hline $\mathrm{MRA}_{-} \mathrm{RO}_{-} \mathrm{E}_{i j r t}$ & $\begin{array}{l}1 \text { if an MRA with rules of origin exists between } \mathrm{i} \text { and any } \\
\text { country other than } \mathrm{j} \text { in industry } \mathrm{r} \text { and year } \mathrm{t} \text {, and } 0 \text { otherwise }\end{array}$ \\
\hline $\mathrm{MRA}_{-} \mathrm{NRO}_{i j r t}$ & $\begin{array}{l}1 \text { if an MRA without rules of origin exists between } i \text { and } j \text { in } \\
\text { industry } r \text { and year } t \text {, and } 0 \text { otherwise }\end{array}$ \\
\hline $\mathrm{MRA}_{-} \mathrm{NRO}_{-} \mathrm{M}_{i j r t}$ & $\begin{array}{l}1 \text { if an MRA without rules of origin exists between } \mathrm{j} \text { and any } \\
\text { country other than } \mathrm{i} \text { in industry } \mathrm{r} \text { and year } \mathrm{t} \text {, and } 0 \text { otherwise }\end{array}$ \\
\hline $\mathrm{MRA}_{-} \mathrm{NRO}_{-} \mathrm{E}_{i j r t}$ & $\begin{array}{l}1 \text { if an MRA without rules of origin exists between } i \text { and any } \\
\text { country other than } i \text { in industry } r \text { and year } t \text {, and } 0 \text { otherwise }\end{array}$ \\
\hline $\mathrm{RTA}_{i j t}$ & 1 if an RTA exists between $\mathrm{i}$ and $\mathrm{j}$, and 0 otherwise \\
\hline $\mathrm{RTA}_{-} \mathrm{M}_{i j t}$ & $\begin{array}{l}1 \text { if an RTA exists between } \mathrm{j} \text { and any country other than } \mathrm{i} \text {, } \\
\text { and } 0 \text { otherwise }\end{array}$ \\
\hline $\mathrm{RTA}_{-} \mathrm{E}_{i j t}$ & $\begin{array}{l}1 \text { if an RTA exists between } i \text { and any country other than } j \text {, } \\
\text { and } 0 \text { otherwise }\end{array}$ \\
\hline
\end{tabular}


$M R A_{-} R O_{i j r t}$ and $M R A_{-} N R O_{i j r t}$ are dummy variables that reflect the existence of an MRA, respectively, with or without the rules of origin between exporter $i$ and importer $j$ in industry $r$ in year $t$. The cases where importer $j$ reaches an MRA with or without the rules of origin with any country other than exporter $i$ are respectively represented by $M R A_{-} R O_{-} M_{i j r t}$ and $M R A_{-} N R O_{-} M_{i j r t}$. The same definitions apply to $M R A_{-} R O_{-} E_{i j r t}$ and $M R A_{-} N R O_{-} E_{i j r t}$ except that the party involved in an MRA is the exporter. The rest of the regressors are dummy variables constructed in a similar fashion to capture the existence of Regional Trade Agreements (RTAs). ${ }^{19}$

\section{Empirical evidence}

In this section, we examine empirically the impact of the different approaches that deal with technical barriers to trade. The main equation we estimate takes the following form:

$$
\ln \left(\text { import }_{i j r t}\right)=\left\{\begin{array}{l}
\alpha+\delta_{i r t}+\eta_{j r t}+\gamma_{i j r} \\
+\beta_{1} H A R_{i j r t}+\beta_{2} H A R_{-} M_{i j r t}+\beta_{3} H A R_{-} E_{i j r t} \\
+\beta_{4} M R A_{-} R O_{i j r t}+\beta_{5} M R A_{-} R O_{-} M_{i j r t}+\beta_{6} M R_{-} R_{-} E_{i j r t} \\
+\beta_{7} M R A_{-} N R O_{i j r t}+\beta_{8} M R A_{-} N R O_{-} M_{i j r t}+\beta_{9} M A_{-} N R O_{-} E_{i j r t} \\
+\beta_{10} R T A_{i j t}+\beta_{11} R T A_{-} M_{i j t}+\beta_{12} R T A_{-} E_{i j t} \\
+\varepsilon_{i j r t}
\end{array}\right.
$$

which can be denoted as $y=X \beta+\varepsilon$ with $y$ representing $\ln \left(\right.$ import $\left._{i j r t}\right), X$ the vector of explanatory variables, $\beta$ the vector of coefficients and $\varepsilon$ the error term.

Three types of fixed effects are included: the nested exporter-industry-year fixed effect captures factors such as sectoral output in the exporting country at a particular time, the nested importer-industry-year fixed effect controls for factors such as sectoral demand and domestic competition in the importing country at a particular time, while the nested importer-exporter-industry fixed effect includes any time-invariant bilateral sectoral ele-

\footnotetext{
${ }^{19}$ We include RTAs effective in our sample countries over the period of 1986-2001, including the EC, EFTA, CEFTA, NAFTA, and the CER (the Closer Economic Relations agreement between Australia and New Zealand).
} 
ments such as distance. The use of these extensive fixed effects enables us to isolate the role of agreements on technical regulations in explaining the changes in the pattern of trade over time.

\subsection{The estimated effects of harmonization and MRAs}

Table 2 reports the estimation results using the Tobit model. Coefficients on all variables are statistically significant at the $1 \%$ level and exhibit the signs predicted in Section 2. Column I reveals that the harmonization directives unambiguously stimulate intraregional trade, as well as trade with excluded countries. In fact, the magnitudes of the estimated impacts are quite large. It would appear that a directive implemented in an industry between two countries on average raises their imports from each other by $32 \%$ $\left(e^{0.2749}=1.32\right)$, and imports from a country outside the harmonizing region by nearly $10 \%$ $\left(e^{0.0950}=1.096\right)$. The boost to trade is attributable to the positive impact of increased scale economies which outweighs, on average, the possible negative effect on trade of increased stringency in some countries' standards.

The impact of an MRA, as predicted in Section 2, turns out to be sensitive to whether it includes restrictive rules of origin. MRAs with rules of origin provide a powerful stimulus to intra-regional trade but at the expense of imports from countries outside the region. ${ }^{20}$ The negative coefficient on $M R A_{-} R O_{-} M,-0.4768$, implies that imports from an excluded country suffer a $38 \%$ decline in affected industries. However, when an MRA does not include restrictive rules of origin, imports from both member countries and third countries increase, indicated by the positive coefficients on both $M R A_{-} N R O$ and $M R A_{-} N R O_{-} M$. Finally, regional trade agreements are found on average to increase trade not only between participating countries but also with the rest of the world. ${ }^{21}$

\footnotetext{
${ }^{20}$ The substantial magnitude of the coefficient on $M R A_{-} R O$ may be explained by the trivial amount of initial trade in the affected industries before the implementation of MRAs.

${ }^{21}$ The literature on the impact of RTA on extra-bloc trade is mixed. Frankel, Stein, and Wei (1997) examine intra- and extra-bloc trade for eight RTAs-EC, EFTA, NAFTA, MERCOSUR, and the Andean Pact, AFTA, the CER, and the East Asian Economic Caucus for the period 1970-1992. Their study suggests that RTAs had positive impacts on all trade flows except for the EC's intra-bloc trade and EFTA's and NAFTA's trade with nonmembers. The authors conclude that there is little trade diversion. Soloaga and Winters (2001) find that RTAs between developing countries increase extra-bloc trade. In particular, ASEAN since 1980 increases intra-bloc trade, extra-bloc imports, and extra-bloc exports. Our estimates suggest that the average effect of these agreements is positive.
} 
Table 2: Estimated effects of harmonization and MRAs

\begin{tabular}{|c|c|c|}
\hline Regressand: $\ln$ (import) & $\mathrm{I}$ & II \\
\hline Harmonization on intra-regional trade & $0.2749 * * *$ & $0.2562^{* * *}$ \\
\hline$(\mathrm{HAR})$ & $(0.010)$ & $(0.011)$ \\
\hline importers with stricter initial standards & & $0.0989^{* * *}$ \\
\hline$($ HAR $\times$ strictness $)$ & & $(0.022)$ \\
\hline Harmonization on imports from the ROW & $0.0950^{* * *}$ & $0.0310^{* * *}$ \\
\hline$\left(\mathrm{HAR}_{-} \mathrm{M}\right)$ & $(0.005)$ & $(0.005)$ \\
\hline importers with stricter initial standards & & $0.2477^{* * *}$ \\
\hline$\left(\mathrm{HAR} \_\mathrm{M} \times\right.$ strictness $)$ & & $(0.011)$ \\
\hline Harmonization on exports to the ROW & $0.6438^{* * *}$ & $0.6393^{* * *}$ \\
\hline$\left(\mathrm{HAR} \_\mathrm{E}\right)$ & $(0.005)$ & $(0.005)$ \\
\hline MRAs with rules of origin on intra-regional trade & $2.3540 * * *$ & $2.3589^{* * *}$ \\
\hline$\left(\mathrm{MRA} \mathrm{RO}_{-}\right)$ & $(0.031)$ & $(0.031)$ \\
\hline MRAs with rules of origin on imports from the ROW & $-0.4768^{* * *}$ & $-0.4799^{* * *}$ \\
\hline$\left(\mathrm{MRA}_{-} \mathrm{RO}_{-} \mathrm{M}\right)$ & $(0.037)$ & $(0.037)$ \\
\hline MRAs with rules of origin on exports to the ROW & $0.3956^{* * *}$ & $0.3963^{* * *}$ \\
\hline$\left(\mathrm{MRA} \mathrm{RO}_{-} \mathrm{E}\right)$ & $(0.036)$ & $(0.036)$ \\
\hline MRAs without rules of origin on intra-regional trade & $0.6362^{* * *}$ & $0.6390^{* * *}$ \\
\hline$\left(\mathrm{MRA}{ }_{-} \mathrm{NRO}\right)$ & $(0.074)$ & $(0.074)$ \\
\hline MRAs without rules of origin on imports from the ROW & $0.7794^{* * *}$ & $0.7950 * * *$ \\
\hline$\left(\mathrm{MRA}{ }_{2} \mathrm{NR} \_\mathrm{M}\right)$ & $(0.037)$ & $(0.037)$ \\
\hline MRAs without rules of origin on exports to the ROW & $1.6235^{* * *}$ & $1.6154^{* * *}$ \\
\hline$\left(\mathrm{MRA}_{-} \mathrm{NRO}_{-} \mathrm{E}\right)$ & $(0.037)$ & $(0.037)$ \\
\hline RTA on intra-regional trade & $1.7225^{* * *}$ & $1.7266^{* * *}$ \\
\hline (RTA) & $(0.011)$ & $(0.011)$ \\
\hline RTA on imports from the ROW & $0.0458^{* * *}$ & $0.0404^{* * *}$ \\
\hline$\left(\mathrm{RTA} \_\mathrm{M}\right)$ & $(0.005)$ & $(0.005)$ \\
\hline RTA on exports to the ROW & $0.0309^{* *}$ & $0.0292^{* * *}$ \\
\hline$(\mathrm{RTA} E \mathrm{E})$ & $(0.005)$ & $(0.005)$ \\
\hline Number of observations & 4160352 & 4160352 \\
\hline Log likelihood & -7840111 & -7839841 \\
\hline
\end{tabular}


In Section 2, Proposition 2 predicted that trade stimulus is negatively correlated with the extent by which the importing country raises its standard - because an increase in the stringency of the standard may partially or completely offset the benefit from market integration and dampens imports. As noted in the introduction, the European Union's richest members generally imposed the most stringent standards, and used their influence to ensure that the EU's harmonized standards were set close to their own levels. The available evidence suggests that the core set of countries with relatively strict initial standards consists of Germany, Denmark, and the Netherlands (Vogel, 1995). We also considered alternative definitions, e.g. the top third of EC and EFTA countries ranked by GDP per capita in 2001, and the results were similar.

An additional interactive term, strictness, is generated to test Proposition 2. For the harmonizing countries which can be presumed to have stricter initial standards, strictness is equal to 1; 0 for the rest of harmonizing importers. In column II of Table 2, the significant coefficient on the variable "HAR $\times$ strictness" confirms that the increase in imports of these two groups of countries differs significantly in magnitude. Intra-regional imports of countries that were likely to have raised their standards during harmonization increase by $29 \%$, considerably less than the $43 \%$ increase for countries with initially stricter standards. This sharp difference is also evident in imports from outside the harmonizing area. Imports of countries with less strict initial standards from a third country increase by $3 \%$, while imports of countries with stricter initial standards increase by $32 \%{ }^{22}$ The rest of the coefficients are similar to those in column I.

\subsection{The divergent impact on imports from third countries}

Do regional agreements in standards have a similar impact on exporters everywhere in the rest of the world? As discussed in Section 2, firms that incur a larger fixed cost of complying with country-specific standards reap larger benefits from scale economies, while firms that incur a higher variable cost of compliance will suffer (benefit) more from any increase (decline) in the stringency of the standard. Any asymmetry in costs can thus be expected

\footnotetext{
${ }^{22}$ As we gradually expand the set of countries deemed to have stricter initial standards (on the basis of GDP per capita), the magnitude of the coefficients on the interacting terms becomes smaller. This tendency indicates that the three countries considered here are appropriate elements of the subset with the most stringent standards.
} 
to lead to quite different effects on exporters in different origins.

As we suggested in Section 2, the distinction between countries according the level of development may correspond to the analytical distinction we make between countries on the basis of their costs of meeting standards. We generate a dummy variable, i.e. developing, which is equal to 1 for a developing country exporter and 0 for a developed country exporter. We consider all OECD countries as developed and the rest of the sample countries as developing. This dummy variable is used to interact with the three variables which capture the impact on imports from third countries: $H A R_{-} M, M R A_{-} R O_{-} M$, and $M R A_{-} N R O_{-} M$. The regression results are reported in column I of Table 3.

While regional harmonization promotes imports from developed third countries by $34 \%$, there is actually a $16 \%$ reduction in imports from the excluded developing world (the coefficient on $H A R_{-} M$ for developing country exporters is -0.1675 and $e^{-0.1675}=$ 0.84). These results are consistent with the assumption, which drives the predictions in Proposition 1 in Section 2, that developing countries tend to find it more costly to meet stricter standards, and reap smaller benefits from economies of scale generated by integrated markets (i.e. $c_{k}<c_{l}$ and $F_{k}>F_{l}$ ).

The impact of MRAs on developing and developed countries turns out to depend on whether they include rules of origin. If they do, they hurt developing country exports (39\% decline) more than they hurt developed country exports (28\% decline). But MRAs without rules of origin enhance developing country exports even more than they enhance developed country exports, revealed by the positive coefficient on the interacting term $M R A_{-} N R O_{-} M \times$ developing. A possible explanation is offered by the intuition behind Proposition 4 in Section 2: the greater reduction in compliance costs for developing country firms may offset the smaller benefits they derive from economies of scale.

Finally, we directly test for the hypotheses in Proposition 1 by comparing respectively the four cases: the importer had more/less stringent initial standards while the exporter is a developed/developing country. Column II of Table 3 shows that with harmonization, exports to countries with stricter initial standards of both developed and developing countries increase, but the increase in the former $(57 \%)$ is much greater than the increase in the latter $(5 \%)$. Developed third countries' exports to countries that raise their stan- 
Table 3: The divergent impact on imports from third countries

\begin{tabular}{|c|c|c|}
\hline Regressand: $\ln$ (import) & I & II \\
\hline Harmonization on intra-regional trade & $0.3002^{* * *}$ & $0.2825^{* * *}$ \\
\hline (HAR) & $(0.010)$ & $(0.011)$ \\
\hline importers with stricter initial standards & & $0.0951^{* * *}$ \\
\hline$(\mathrm{HAR} \times$ strictness $)$ & & $(0.023)$ \\
\hline Harmonization on imports from the ROW & $0.2912^{* * *}$ & \\
\hline$\left(\mathrm{HAR} \_\mathrm{M}\right)$ & $(0.007)$ & \\
\hline from developing countries & $-0.4587^{* * *}$ & \\
\hline$\left(\mathrm{HAR} \_\mathrm{M} \times\right.$ developing $)$ & $(0.012)$ & \\
\hline from developed countries to importers with stricter initial standards & & $0.4491^{* * *}$ \\
\hline$\left(\mathrm{HAR} \_\mathrm{M}\right.$ with developing $=0 \&$ strictness $\left.=1\right)$ & & $(0.014)$ \\
\hline from developing countries to importers with stricter initial standards & & $0.0458^{* * *}$ \\
\hline$($ HAR_M with developing $=1 \&$ strictness $=1)$ & & $(0.017)$ \\
\hline from developed countries to importers with less strict initial standards & & $0.2369^{* * *}$ \\
\hline$\left(\mathrm{HAR}_{-} \mathrm{M}\right.$ with developing $=0 \&$ strictness $\left.=0\right)$ & & $(0.008)$ \\
\hline from developing countries to importers with less strict initial standards & & $-0.2421^{* * *}$ \\
\hline$\left(\mathrm{HAR} \_\mathrm{M}\right.$ with developing $=1 \&$ strictness $\left.=0\right)$ & & $(0.010)$ \\
\hline Harmonization on exports to the ROW & $0.6357 * * *$ & $0.6315^{* * *}$ \\
\hline$\left(\mathrm{HAR}_{-} \mathrm{E}\right)$ & $(0.005)$ & $(0.005)$ \\
\hline MRAs with rules of origin on intra-regional trade & $2.3185^{* * *}$ & $2.3233^{* * *}$ \\
\hline$\left(\mathrm{MRA} \mathrm{RO}_{-}\right.$ & $(0.031)$ & $(0.031)$ \\
\hline MRAs with rules of origin on imports from the ROW & $-0.3294^{* * *}$ & $-0.3334^{* * *}$ \\
\hline$\left(\mathrm{MRA}_{-} \mathrm{RO}_{-} \mathrm{M}\right)$ & $(0.041)$ & $(0.041)$ \\
\hline from developing countries & $-0.1792^{* * *}$ & $-0.1763^{* * *}$ \\
\hline$\left(\mathrm{MRA}{ }_{-} \mathrm{RO} \_\mathrm{M} \times\right.$ Developing$)$ & $(0.044)$ & $(0.044)$ \\
\hline MRAs with rules of origin on exports to the ROW & $0.3204^{* * *}$ & $0.3213^{* * *}$ \\
\hline$\left(\mathrm{MRA}{ }_{-} \mathrm{RO} \_\mathrm{E}\right)$ & $(0.036)$ & $(0.036)$ \\
\hline MRAs without rules of origin on intra-regional trade & $0.6612^{* * *}$ & $0.6641^{* * *}$ \\
\hline$\left(\mathrm{MRA}{ }_{-} \mathrm{NRO}\right)$ & $(0.075)$ & $(0.075)$ \\
\hline MRAs without rules of origin on imports from the ROW & $0.8237^{* * *}$ & $0.8379^{* * *}$ \\
\hline$\left(\mathrm{MRA}{ }_{-} \mathrm{NRO}_{-} \mathrm{M}\right)$ & $(0.040)$ & $(0.040)$ \\
\hline from developing countries & $0.2267^{* * *}$ & $0.2296^{* * *}$ \\
\hline$\left(\mathrm{MRA} \_\mathrm{NRO} \_\mathrm{M} \times\right.$ Developing$)$ & $(0.041)$ & $(0.041)$ \\
\hline MRAs without rules of origin on exports to the ROW & $1.5031^{* * *}$ & $1.4952^{* * *}$ \\
\hline$\left(\mathrm{MRA} \mathrm{NRO}_{-} \mathrm{E}\right)$ & $(0.037)$ & $(0.037)$ \\
\hline RTA on intra-regional trade & $1.7331^{* * *}$ & $1.7371^{* * *}$ \\
\hline RTA on imports from the ROW & $0.0347 * * *$ & $0.0295^{* * *}$ \\
\hline RTA on exports to the ROW & 0.004 & 0.0027 \\
\hline
\end{tabular}


dards also rise (by 27\%), but developing countries' exports decline by $22 \%$. These results are consistent with the predictions in Proposition 1, and the assumption that developing countries benefit less from economies of scale, and thus see a smaller increase in exports to the market that does not increase the stringency of its standard and are hurt more by an increase in the stringency of the standards in other markets to which their exports decline.

These findings suggest that harmonization of standards is generally advantageous to participating and excluded developed countries that have similar cost structures, but could hurt the exports of developing countries. In the case of mutual recognition agreements, excluded developed and developing countries have greater commonness of cause: absent rules of origin both gain, with rules of origin both lose, with a larger impact on developing countries in each case.

\section{Robustness analysis}

Our econometric results have been obtained with a range of controls designed to eliminate any correlation between the endogenous variables and the error term. However, we cannot rule out econometric problems arising for two reasons: omission of unobserved effects and endogeneity of regressors. First of all, initiatives on standards may not be the only measures that have drawn the countries of the European Union to trade closer together. For example, it could be that liberalization of transport inside the EU has reduced the costs of transport inside the Union faster than the costs outside the Union. Secondly, it may be that the initiatives on standards have been taken in precisely those industries in which trade between members was growing, so the initiatives are at least in part the results rather than the cause of trade growth. In this section we address these concerns and test the robustness of our results.

\subsection{Unobserved effects}

We first consider the possible omission of unobserved effects, which are not already embodied in the multiple nested fixed effects included in Section 4. Such effects must therefore 
consist of time-variant bilateral factors such as the preferential political or economic relations between two countries that might be correlated with the explanatory variables of interest.

Following the approach suggested in Baltagi (2001) and originally due to Mundlak (1978) on individual effects, we attempt to test and capture this time-variant bilateral effect, denoted by $\mu_{i j t}$, by assuming $\mu_{i j t}$ is a linear function of the averages of all the existing explanatory variables (measures of regional initiatives) across industries:

$$
\mu_{i j t}=\bar{X}_{i j t .} \pi+v_{i j t}
$$

where $\bar{X}_{i j t}$. is a $1 \times R$ vector of observations on the explanatory variables averaged across industries. This effect is uncorrelated with the explanatory variables if and only if $\pi=0$. As Mundlak (1978) assumed, without loss of generality, the $X$ are deviations from their sample mean. The main equation to be estimated becomes:

$$
y=X \beta+P X \pi+\epsilon,
$$

where $P=I_{N} \otimes I_{N} \otimes I_{T} \otimes \bar{J}_{R}$, and the new error term has zero mean.

The estimation results with the control of unobserved time-variant bilateral effect are reported in Table 4. The coefficient on $P X$ is statistically significant and positive, rejecting the null of zero correlation between the unobserved effect and explanatory variables. It suggests that over time a stronger bilateral relationship leads to a larger amount of sectoral trade. Furthermore, note that the magnitude of most estimates has fallen except for the coefficients on $H A R$ and $M R A_{-} R O$, compared to column I in Table 2. This result shows that consideration of the unobserved effect reduces the explanatory power of most of the regressors but not of intra-EU harmonization and MRA with rules of origin. ${ }^{23}$ While this test cannot be regarded as conclusive, at least the inclusion of a measure of unobserved effects does not alter our qualitative conclusions.

\footnotetext{
${ }^{23}$ The considerable decrease in the coefficients of $R T A$ variables with the inclusion of $\mu_{i j t}$ is not surprising, since $R T A$ variables also measure time-variant bilateral relations.
} 
Table 4: Robustness analysis: unobserved effects

\begin{tabular}{ll}
\hline \hline Regressand: ln(import) & \multicolumn{1}{c}{$\mathrm{I}$} \\
\hline Harmonization on intra-regional trade & $0.4561^{* * *}$ \\
(HAR) & $(0.010)$ \\
Harmonization on imports from the ROW & $0.0515^{* * *}$ \\
(HAR_M) & $(0.005)$ \\
Harmonization on exports to the ROW & $0.6046^{* * *}$ \\
(HAR_E) & $(0.005)$ \\
MRAs with rules of origin on intra-regional trade & $2.4154^{* * *}$ \\
(MRA_RO) & $(0.031)$ \\
MRAs with rules of origin on imports from the ROW & $-0.7087^{* * *}$ \\
(MRA_RO_M) & $(0.037)$ \\
MRAs with rules of origin on exports to the ROW & $0.1738^{* * *}$ \\
(MRA_RO_E) & $(0.036)$ \\
MRAs without rules of origin on intra-regional trade & $0.3197^{* * *}$ \\
(MRA_NRO) & $(0.074)$ \\
MRAs without rules of origin on imports from the ROW & $0.2512^{* * *}$ \\
(MRA_NRO_M) & $(0.037)$ \\
MRAs without rules of origin on exports to the ROW & $1.1430^{* * *}$ \\
(MRA_NRO_E) & $(0.037)$ \\
RTA on intra-regional trade & \\
(RTA) & \\
RTA on imports from the ROW & $0.0539^{* * *}$ \\
(RTA_M) & $(0.019)$ \\
\hline \hline
\end{tabular}




\subsection{Endogenous regressors}

The problem of endogenous regressors would lead to an overestimation of the tradeenhancing effect of initiatives on standards if the initiatives were implemented where trade was already growing rapidly. Formally, this concern can be expressed as

$$
\begin{aligned}
& x=1 \text { if } x^{*}>0 \\
& x=0 \text { otherwise, }
\end{aligned}
$$

where $x$ refers to the endogenous regressor in the vector of explanatory variables $X$, and $x^{*}=\gamma^{\prime} Z+v$ where $Z$ represents a vector of exogenous/predetermined variables.

To correct for the endogeneity, we first use the Instrumental Variable (IV) approach. If prior growth in trade led to the policy initiatives, then it would be appropriate to use the lagged three-year average trade growth, i.e. $\operatorname{growth}_{i j r(t-1)}(\equiv Z)$, as an instrument. To avoid the problem of identification, we construct a comprehensive indicator, denoted by $I N I$, that considers all the policy initiatives, i.e. harmonization, MRA with rules of origin, and MRA without rules origin: $I N I=1$ if there exist any of the above initiatives between the exporter and the importer at an industry in a particular year and 0 otherwise.

Column II of Table 5 reports the two-stage IV estimation results, while column I reports the benchmark results where the potential endogeneity of regressors is not corrected. In the first stage, the effect of lagged average trade growth on the initiatives, estimated in a probit model, is significantly negative. This result suggests that two countries are more likely to take a standards-related initiative in situations of relatively slow growth of bilateral trade. In the second stage, we find that a $10 \%$ increase in the likelihood of an initiative is associated with a $76 \%$ increase in trade. Put differently, the estimated effect of $I N I$ after correcting for possible endogeneity is 1.5544 , which is significantly larger than the estimated effect reported in column I. These results suggest that if there were an endogeneity problem, failure to correct for it would lead to an underestimation of the impact of the initiatives.

As an alternative to the IV approach, we adopt the two-step estimator proposed by 
Table 5: Robustness analysis: endogenous regressors

\begin{tabular}{llll}
\hline \hline & \multicolumn{1}{c}{ I } & II & III \\
\hline Stage 1: & & & \\
Initiative on lagged three-year average trade growth & - & $-0.1583^{* * *}$ & $-0.1583^{* * *}$ \\
& & & \\
Stage 2: Regressand: ln(imports) & & & \\
Initiative on intra-regional trade / & $1.4821^{* * *}$ & $1.5544^{* * *} /$ & $1.5010^{* * *}$ \\
Probability of the initiative on intra-regional trade & & $5.6690^{* * *}$ & \\
(INI / INI_PROB) & $(0.021)$ & $(0.021)$ & $(0.020)$ \\
Initiative on imports from the ROW & $-0.0193^{*}$ & $0.3020^{* * *}$ & $0.0618^{* * *}$ \\
(INI_M) & $(0.010)$ & $(0.010)$ & $(0.010)$ \\
Initiative on exports to the ROW & $1.1464^{* * *}$ & $1.3365^{* * *}$ & $1.07^{* * *}$ \\
(INI_E) & $(0.010)$ & $(0.009)$ & $(0.010)$ \\
& & & \\
RTA on intra-regional trade & $1.8908^{* * *}$ & $2.1206^{* * *}$ & $1.6474^{* * *}$ \\
(RTA) & $(0.013)$ & $(0.012)$ & $(0.013)$ \\
RTA on imports from the ROW & $0.0911^{* * *}$ & $-0.0450^{* * *}$ & $-0.0471^{* * *}$ \\
(RTA_M) & $(0.006)$ & $(0.006)$ & $(0.006)$ \\
RTA on exports to the ROW & -0.0091 & $-0.0919^{* * *}$ & $-0.0787^{* * *}$ \\
(RTA_E) & $(0.006)$ & $(0.006)$ & $(0.006)$ \\
Generalized residual & & & - \\
Number of observations & -4598521 & -4566748 & -4536913 \\
Log likelihood & & & $6.4712^{* * *}$ \\
\hline \hline
\end{tabular}


Vella (1993) which deals with censored endogenous regressors. ${ }^{24}$ As in the previous IV approach, we first estimate the effect of the lagged three-year average trade growth on standards-related initiatives. Then we compute the generalized residual from the first stage, i.e. $E(\hat{v} \mid x)$, to be included as an additional regressor in our original estimating equation in column I. The original equation can be rewritten in terms of its conditional expectation as follows:

$$
E(y \mid x)=X \beta+\lambda E(\hat{v} \mid x) .
$$

The two-step estimators are reported in column III of Table 5. The estimates obtained in the second stage again confirm that correcting for endogeneity associated with the prior trade growth rates leads to a slight upward revision of the impact of initiatives.

\section{Conclusion}

This paper has analyzed the implications for trade of various regional initiatives that deal with technical barriers. Both analytically and empirically, we found that harmonization and mutual recognition can have a significant positive impact on trade within the region and with third countries. But there is a qualification in each case. If the harmonized standard is stricter than the initial standard in some countries, then the benefits from market integration in terms of economies of scale can be offset by the increased production cost due to a stricter standard. Countries with stricter initial standards witness a larger increase in imports relative to those with less strict initial standards. Exports of developing countries to the harmonizing region differ sharply across destinations: their exports to countries that raise their standards fall, whereas exports to the harmonizing countries with stricter initial standards rise moderately.

When mutual recognition agreements contain restrictive rules of origin, then their benefits are confined to countries within the region at the expense of imports from the rest

\footnotetext{
${ }^{24}$ Vella (1993) unifies the literature on censored endogenous regressors and self-selectivity bias, and employs generalized residuals to adjust for the inconsistency caused by the endogeneity of the censored regressors. The estimator proposed by this procedure (with binary censored endogenous variable), in the case where $X$ does not contain an intercept and only values of $y$ corresponding to specific values of $x$ are observed, is essentially the two-step estimator in Heckman (1979) that corrects the self-selectivity bias. Hausman (1978) also argues that inconsistency due to the endogeneity of regressors can be adjusted by the inclusion of the residuals in place of the predicted values of the endogenous variable.
} 
of the world, in particular, developing countries. When MRAs are open to firms regardless of origins, both intra-regional trade and trade with the rest of the world, especially with developing countries, rise substantially.

We noted in the introduction that multilateral rules on goods trade have taken a permissive approach to regional agreement on standards. It is neither feasible nor desirable to restrict the freedom of countries to harmonize or mutually recognize their standards. However, more could be done to protect the rights of countries that are excluded from such agreements. This is particularly important because few of the agreements on standards include developing countries, and the big differences in social preferences over issues such as safety and the environment suggest that few developing countries are likely to be party to such agreements with industrial countries in the foreseeable future. Multilateral rules should make it more difficult to conclude agreements of the type that impose an unnecessarily high price of exclusion, especially on developing countries. Thus, the imposition of restrictive rules of origin, which deny the benefits of mutual recognition agreements to third countries for no legitimate reason, should be outlawed. It is harder to prevent the upward harmonization of standards. But it may be possible to build on the presumption that international trade law already creates in favor of the use of international standards by individual countries (in Articles 2.4 and 2.5 of the WTO's Agreement on Technical Barriers to Trade) and oblige countries that harmonize their standards to demonstrate why international standards or the less strict of the original standards are not adequate to meet their regulatory goals.

This paper should be seen as the beginning of a research program, and there remains much scope for deepening the analysis. In particular, two types of industry-level data would help: first, on how the level of harmonized standards compares with the standards that countries originally imposed; second, the implications of complying with standards for the cost of firms, across industries and countries. Such data would make it feasible to carry out the industry-level analysis that would ideally be the next step in this research program. 


\section{Appendix A}

Table A.1: The New Approach Directives

\begin{tabular}{ll}
\hline \hline Directives & Reference \\
\hline Low voltage equipment & $73 / 23 / \mathrm{EEC}$ \\
Simple pressure vessels & $97 / 23 / \mathrm{EC}$ \\
Toys & $88 / 378 / \mathrm{EEC}$ \\
Construction products & $89 / 106 / \mathrm{EEC}$ \\
Electromagnetic compatibility & $89 / 336 / \mathrm{EEC}$ \\
Machinery & $98 / 37 / \mathrm{EC}$ \\
Personal protective equipment & $89 / 686 / \mathrm{EEC}$ \\
Non-automatic weighing instruments & $90 / 384 / \mathrm{EEC}$ \\
Active implantable medical devices & $90 / 385 / \mathrm{EEC}$ \\
Gas appliances & $90 / 396 / \mathrm{EEC}$ \\
Hot water boilers & $92 / 42 / \mathrm{EEC}$ \\
Civil explosives & $93 / 15 / \mathrm{EEC}$ \\
Medical devices & $93 / 42 / \mathrm{EEC}$ \\
Potentially explosive atmospheres & $94 / 9 / \mathrm{EEC}$ \\
Recreational craft & $94 / 25 / \mathrm{EC}$ \\
Lifts & $95 / 16 / \mathrm{EC}$ \\
Refrigeration appliances & $96 / 57 / \mathrm{EC}$ \\
Pressure equipment & $97 / 23 / \mathrm{EC}$ \\
In vitro diagnostic medical devices & $98 / 79 / \mathrm{EC}$ \\
Radio and telecommunications terminal equipment & $99 / 5 / \mathrm{EC}$ \\
Cable installation designed to carry person & $00 / 9 / \mathrm{EC}$ \\
Packaging and packaging waste & $94 / 62 / \mathrm{EC}$ \\
High speed rail systems & $96 / 48 / \mathrm{EC}$ \\
Marine equipment & $96 / 98 / \mathrm{EC}$ \\
\hline \hline
\end{tabular}

Table A.2: The MRAs of Conformity Assessment

\begin{tabular}{lc}
\hline \hline MRA of Conformity Assessment & Rules of Origin \\
\hline EU and Australia & Yes \\
EU and New Zealand & Yes \\
EFTA and Australia & Yes \\
EFTA and New Zealand & Yes \\
INTRA EU & Yes \\
EU and USA & No \\
EU and Canada & No \\
Australia and New Zealand & No \\
Canada and Korea & No \\
Canada and Swiss & No \\
\hline \hline
\end{tabular}




\section{Appendix B.1: Proof for Proposition 1.}

Proof. (i) In markets with strictest initial standards, $d s_{j}=0$ and $d N_{j}>0$, and thus equation (7) becomes

$$
d Q_{i j}=\frac{1}{\gamma_{i j}} \sum_{z}\left[\phi_{i j} \sum_{m}\left(\frac{\partial n_{z j}}{\partial n_{m j}} V_{m j}^{*}\right)+\vartheta_{i j} V_{z j}^{*}\right] d N_{j}
$$

where $\phi_{i j} \equiv n_{i j} \partial q_{i j}^{*} / \partial n_{i z}$ and $\vartheta_{i j} \equiv q_{i j}^{*} \partial n_{i j} / \partial n_{i z}$. Equation (a.1) can be further simplified as

$$
d Q_{i j}=\frac{d Q_{i j}}{d n_{i j}} \sum_{z} \frac{\partial n_{i j}}{\partial n_{z j}} \frac{V_{z j}^{*}}{\gamma_{i j}} d N_{j}
$$

where $d Q_{i j} / d n_{i j}=\partial Q_{i j} / \partial n_{i j}+\sum_{z}\left(\partial Q_{i j} / \partial n_{z j}\right)\left(\partial n_{z j} / \partial n_{i j}\right)$. Denote $\varphi_{i j} \equiv\left(d Q_{i j} / d n_{i j}\right)$ $\sum_{z}\left(\partial n_{i j} / \partial n_{z j}\right)\left(V_{z j}^{*} / \gamma_{i j}\right)$.

Provided that $\partial P_{j}^{*} / \partial Q_{i j}>S O C_{i j} / n_{i j}\left(S O C_{i j} \equiv 2\left(\partial P_{j} / \partial Q_{i j}\right) n_{i j}\right.$ denotes the secondorder condition to maximize $\left.\Pi_{i j}\right),-q_{i j}^{*} / n_{i j}<\partial q_{i j}^{*} / \partial n_{i j}=-q_{i j}^{*}\left(\partial P_{j} / \partial Q_{i j}\right) / S O C<0$ and thus $\partial Q_{i j} / \partial n_{i j}=q_{i j}^{*}+n_{i j} \partial q_{i j}^{*} / \partial n_{i j}>0$. Furthermore, we find

$$
\begin{aligned}
\partial V_{z j}^{*} / \partial n_{i j} & =\frac{\partial\left(P_{j}^{*} Q_{z j}\right)}{\partial n_{i j}}-c_{z} s_{j} \frac{\partial q_{z j}^{*}}{\partial n_{i j}} \\
& =\frac{\partial P_{j}^{*}}{\partial Q_{i j}} \frac{\partial Q_{i j}}{\partial n_{i j}}+\left[\left(Q_{z j} \frac{\partial P_{j}^{*}}{\partial Q_{z j}}+P_{j}^{*}\right) n_{z j}-c_{z} s_{j}\right] \frac{\partial q_{z j}}{\partial n_{i j}} \\
& <0
\end{aligned}
$$

because $\partial P_{j}^{*} / \partial Q_{m j}<0 \forall m$ (the negative slope of the demand function),

$$
\frac{\partial Q_{i j}}{\partial n_{i j}}=q_{i j}^{*}+n_{i j} \frac{\partial q_{i j}}{\partial n_{i j}}=q_{i j}^{*}\left[1-\frac{\partial P_{j}}{\partial Q_{i j}} \frac{n_{i j}}{S O C_{i j}}\right]=\frac{1}{2} q_{i j}^{*}>0
$$

$\left(\partial P_{j}^{*} / \partial Q_{z j}\right) Q_{z j}+P_{j}^{*}=c_{z} s_{j}$ at profit maximization, and $\partial q_{z j} / \partial n_{i j}<0$. Thus,

$$
\partial n_{z j} / \partial n_{i j}=-\frac{\left(\bar{n} N_{j} / \Delta F\right)\left(\partial V_{z j}^{*} / \partial n_{i j}\right)}{\left(\bar{n} N_{j} / \Delta F\right)\left(\partial V_{z j}^{*} / \partial n_{z j}\right)-1}<0
$$


In addition, we know $\partial Q_{i j} / \partial n_{z j}=q_{i j}^{*} \partial n_{i j} / \partial n_{z j}+n_{i j} \partial q_{i j}^{*} / \partial n_{z j}<0$. Hence, $d Q_{i j} / d n_{i j}>0$.

Moreover, because $\partial P_{j}^{*} / \partial Q_{k j}=\partial P_{j}^{*} / \partial Q_{l j}$ (products that meet the same standard are identical to consumers regardless of the production location) and $q_{k j}^{*}>q_{l j}^{*}$, we find $\partial q_{z j} / \partial n_{k j}<\partial q_{z j} / \partial n_{l j}$ (where $\left.\partial q_{z j} / \partial n_{i j}=-q_{i j}^{*}\left(\partial P_{j} / \partial Q_{i j}\right) / S O C_{z j}\right)$, as well as $\left(\partial P_{j}^{*} / \partial Q_{k j}\right)\left(\partial Q_{k j} / \partial n_{k j}\right)<\left(\partial P_{j}^{*} / \partial Q_{l j}\right)\left(\partial Q_{l j} / \partial n_{l j}\right)$ (where $\partial Q_{i j} / \partial n_{i j}$ is defined in (a.5)). Therefore, $\partial V_{z j}^{*} / \partial n_{k j}<\partial V_{z j}^{*} / \partial n_{l j}<0$, which unambiguously leads to $\partial n_{k j} / \partial n_{l j}>-1$.

Because the profit-maximizing reaction function, i.e. $q_{i j}=f\left(\left.q_{z j}\right|_{z \neq i}\right)$, is a strictly decreasing function of $c_{i}$, given by

$$
\frac{\partial q_{i j}}{\partial c_{i}}=\frac{s_{j}}{\partial^{2} R_{i j} / \partial q_{i j}^{2}}<0
$$

where $\partial^{2} R_{i j} / \partial q_{i j}^{2}<0$. At equilibrium, $\partial q_{i j}^{*} / \partial c_{i}<0$. We find that $V_{i j}^{*}$ is also strictly decreasing when $c_{i}$ rises, because

$$
\frac{\partial V_{i j}^{*}}{\partial c_{i}}=\frac{\partial R_{i j}}{\partial q_{i j}} \frac{\partial q_{i j}^{*}}{\partial c_{i}}-s_{j}\left(q_{i j}^{*}-c_{i} \frac{\partial q_{i j}^{*}}{\partial c_{i}}\right)<0
$$

given $\partial R_{i j} / \partial q_{i j}>0$ and $\partial q_{i j}^{*} / \partial c_{i}<0$. Thus, $V_{k j}^{*}>V_{l j}^{*}$. Because $V_{k j}^{*}>V_{l j}^{*}>-\left(\partial n_{k j} / \partial n_{l j}\right)$ $V_{l j}^{*}, \varphi_{k j}>0$ and $d Q_{k j}>0$.

As for $d Q_{l j}$, when $d s_{j}=0, d Q_{l j}>0$ (i.e. $\varphi_{l j}>0$ ) if and only if $V_{l j}^{*} / V_{k j}^{*}>-\partial n_{l j} / \partial n_{k j}$, where $V_{i j}^{*} \equiv\left(P_{j}^{*}-c_{i} s_{j} q_{i j}^{*}\right)$ for $i=k, l$. The above condition holds when $\left(\left(P_{j}^{*}-c_{l} s_{j}\right) q_{l j}^{*} /\left(P_{j}^{*}-\right.\right.$ $\left.\left.c_{k} s_{j}\right) q_{k j}^{*}=\right)\left(P_{j}^{*}-c_{l} s_{j}\right)^{2} /\left(P_{j}^{*}-c_{k} s_{j}\right)^{2}>-\partial n_{k j} / \partial n_{l j}$, where $P_{j}^{*}>c_{i} s_{j}, \partial n_{k j} / \partial n_{l j}$ is defined in (a.3) with $i=k$, and the first equality follows, at profit maximum, $P_{j}^{*}-\partial P_{j} / \partial q_{i j}-c_{i} s_{j}=$ 0 . When $c_{l}<\bar{g}\left(c_{k}\right) \equiv 1 / s_{j}\left[P_{j}+\bar{b}\left(P_{j}-c_{k} s_{j}\right)\right]$ where $\bar{b} \equiv-\left[-\left(N_{j} / \gamma_{l j}\right)\left(\partial V_{l j}^{*} / \partial n_{k j}\right)\right]^{1 / 2}$, $\left(P_{j}^{*}-c_{l} s_{j}\right)^{2} /\left(P_{j}^{*}-c_{k} s_{j}\right)^{2}>-\partial n_{k j} / \partial n_{l j}, \varphi_{l j}>0$ and thus $d Q_{l j}>0$; when $c_{l}>\bar{g}\left(c_{k}\right)$, $d Q_{l j}<0$.

(ii) In contrast, in markets with less strict initial standards, $d s_{j}>0$ and $d N_{j}>0$. Equation (7) becomes

$$
d Q_{i j}=\frac{d Q_{i j}}{d n_{i j}} \sum_{z} \frac{\partial n_{i j}}{\partial n_{z j}} \frac{V_{z j}^{*}}{\gamma_{i j}} d N_{j}+\left[n_{i j}^{*} \frac{\partial q_{i j}^{*}}{\partial s_{j}}+\frac{N_{j}}{\gamma_{i j}} \frac{d Q_{i j}}{d n_{i j}} \sum_{z}\left(\frac{\partial n_{i j}}{\partial n_{z j}} \frac{\partial V_{z j}}{\partial s_{j}}\right)\right] d s_{j}
$$


Denote $\psi_{i j} \equiv n_{i j}^{*}\left(\partial q_{i j}^{*} / \partial s_{j}\right)+N_{j} / \gamma_{i j}\left(d Q_{i j} / d n_{i j}\right) \sum_{z}\left(\partial n_{i j} / \partial n_{z j}\right)\left(\partial V_{z j} / \partial s_{j}\right)$.

Because

$$
\frac{\partial n_{i j}}{\partial c_{i}}=\gamma_{i j} N_{j} \frac{\partial V_{i j}^{*}}{\partial c_{i}}<0
$$

we find $n_{k j}<n_{l j}$. Furthermore,

$$
\frac{\partial q_{i j}^{*}}{\partial s_{j}}=\frac{\frac{\partial P_{j}}{\partial s_{j}}-c_{i}}{-S O C}<0
$$

because $c_{i}>\partial P_{j} / \partial s_{j}$, and $S O C<0$. Given $c_{k}<c_{l}$, we obtain $\partial q_{l j}^{*} / \partial s_{j}<\partial q_{k j}^{*} / \partial s_{j}<0$. Thus $n_{l j}^{*} \partial q_{l j}^{*} / \partial s_{j}<n_{k j}^{*} \partial q_{k j}^{*} / \partial s_{j}<0$, where $n_{i j}^{*} \partial q_{i j}^{*} / \partial s_{j}$ denotes the direct effect of an increase in $s_{j}$ that appears in equation (a.8). The second multiplier of $d s_{j}$ in equation (a.8) denotes the indirect effect of an increase in $s_{j}$. We consider $c_{i}>\underline{c} \equiv \partial P_{j}^{*} / \partial s_{j}+$ $\left(N_{j} / \gamma_{i j}\right)\left(d Q_{i j} / d n_{i j}\right) \sum_{z}\left[\left(\partial n_{i j} / \partial n_{z j}\right)\left(\partial V_{z j} / \partial s_{j}\right)\right] S O C / n_{i j}^{*}$, which indicates the negative net effect of an increase in $s_{j}$, i.e. $\psi_{i j}<0$. Denote the solution of $d s_{j}$ that sets (a.8) to zero as $\Delta \underline{s}$ for $i=k$, which yields $\Delta \underline{s}=-\left(\varphi_{k j} / \psi_{k j}\right) d N_{j}>0$. We conclude $d Q_{k j}>0$ when $d s_{j}<\Delta \underline{s}$ while $d Q_{k j}<0$ otherwise.

When $d s_{j}>0$, given another additional negative impact on $d Q_{l j}$ arising from $d s_{j}>0$, we know $d Q_{l j}<0$ when $c_{l}>\bar{g}\left(c_{k}\right)$. When $c_{l}<\bar{g}\left(c_{k}\right), d Q_{l j}<0$ if and only if $V_{l j}^{*} / V_{k j}^{*}<$ $-\psi_{l j}\left(d s_{j} / d N_{j}\right) 1 /\left[\left(d Q_{i j} / d n_{i j}\right) / V_{k j}\right]-\partial n_{l j} / \partial n_{k j}$ where $\psi_{i j}<0$. The above condition holds when $c_{l}>\underline{g}\left(c_{k}\right) \equiv 1 / s_{j}\left[P_{j}+\underline{b}\left(P_{j}-c_{k} s_{j}\right)\right]$ where $\underline{b} \equiv-\left[-\psi\left(d s_{j} / d N_{j}\right) 1 /\left[\left(d Q_{i j} / d n_{i j}\right) / V_{k j}\right]-\right.$ $\left.\left(N_{j} / \gamma_{l j}\right)\left(\partial V_{l j}^{*} / \partial n_{k j}\right)\right]^{1 / 2}$. Because $\underline{b}<\bar{b}, \underline{g}\left(c_{k}\right)<\bar{g}\left(c_{k}\right)$. Thus, we conclude that, when $d s_{j}>0$ and $c_{l}>\underline{g}\left(c_{k}\right), d Q_{l j}<0$.

\section{Appendix B.2: Proof for Proposition 2.}

Proof. As suggested in Appendix B.1, when $c_{i}>\tilde{c}$, the net effect of an increase in $s_{j}$ is negative. Comparing the harmonizing markets of $d s_{j}=0$ with those of $d s_{j}>0$, we find that, in the latter markets, the positive market integration effect may be partially or even completely offset by the negative effect of $d s_{j}>0$. Thus, the increase in imports of harmonizing market $j$, i.e. $d Q_{i j}$, from any exporter $i$ is a strictly decreasing function of 
$d s_{j}$.

\section{Appendix B.3: Proof for Proposition 3.}

Proof. (i) In the case of mutual recognition with restrictive rules of origin, $d n_{i j}>0$ for $i, j \in H$ because $d N_{j}>0$ and $d s_{j} \leqslant 0$, and $d n_{z j}=0$ for $z \notin H$ in equation (6). Thus $d n_{i j}^{*}>0$ and $d n_{z j}^{*}<0$. As a result, for $i, j \in H$, given $d s_{j} \leqslant 0, d n_{i j}^{*}>0, d n_{z j}^{*}<0$, and $\partial n_{i j} / \partial n_{z j}<0, d Q_{i j}>0$ in equation (4). For $i \in H, z \notin H$, and $j \in H$,

$$
\frac{d Q_{z j}}{d n_{i j}}=\frac{\partial Q_{z j}}{\partial n_{i j}}+\frac{d Q_{z j}}{d n_{z j}} \frac{\partial n_{z j}}{\partial n_{i j}}<0
$$

and thus given $d s_{j}=0$ and $d n_{i j}^{*}>0, d Q_{z j}<0$.

(ii) For $k, l \notin H, j \in H$,

$$
\begin{aligned}
\frac{d\left(Q_{l j}-Q_{k j}\right)}{d n_{i j}} & =\frac{d\left(n_{l j} q_{l j}-n_{k j} q_{k j}\right)}{d n_{i j}} \\
& =n_{l j} \frac{d q_{l j}}{d n_{i j}}-n_{k j} \frac{d q_{k j}}{d n_{i j}}+q_{l j} \frac{\partial n_{l j}}{\partial n_{i j}}-q_{k j} \frac{\partial n_{k j}}{\partial n_{i j}}
\end{aligned}
$$

Note $n_{l j} / n_{k j}>d q_{k j} / d q_{l j}$, because

$$
\begin{aligned}
d q_{k j} / d q_{l j} & =\frac{\left(\partial P_{j}^{*} / \partial Q_{j}\right)\left(\partial Q_{j} / \partial q_{l j}\right)}{\left(\partial P_{j}^{*} / \partial Q_{j}\right)\left(\partial Q_{j} / \partial q_{k j}\right)+1} \\
& =\frac{\left(\partial P_{j}^{*} / \partial Q_{j}\right) n_{l j}}{\left(\partial P_{j}^{*} / \partial Q_{j}\right) n_{k j}+1}<\frac{n_{l j}}{n_{k j}}
\end{aligned}
$$

Therefore, $n_{l j} d q_{l j} / d n_{i j}<n_{k j} d q_{k j} / d n_{i j}$. When $c_{l}>g_{1}\left(c_{k}\right) \equiv 1 / s_{j}\left[P_{j}+\underline{b}^{\prime}\left(P_{j}-c_{k} s_{j}\right)\right]$ where $\underline{b}^{\prime} \equiv \gamma_{l j} /\left(N_{j} \partial V_{l j}^{*} / \partial n_{k j}\right), \partial n_{l j} / \partial n_{k j}<-q_{k j} / q_{l j}$, and $q_{l j} \partial n_{l j} / \partial n_{i j}<q_{k j} \partial n_{k j} / \partial n_{i j}$ given $\partial n_{k j} / \partial n_{i j}=-1$ with $i \in H, k \notin H$. Therefore, $d\left(Q_{l j}-Q_{k j}\right) / d n_{i j}$ defined in equation (a.12) is negative. Given $d n_{i j}^{*}>0, d\left(Q_{l j}-Q_{k j}\right)<0$ and thus $d Q_{l j}<d Q_{k j}<0$.

\section{Appendix B.4: Proof for Proposition 4.}

Proof. (i) In the case of mutual recognition without rules of origin, $d N_{j}>0$ and $d s_{j} \leqslant 0$ 
for exporters of all origins. When the exporter countries are type $K$ (either within the region or in the rest of the world) or type $L$ with $c_{l}<\bar{g}\left(c_{k}\right)$, the effects of both $d N_{j}>0$ and $d s_{j} \leqslant 0$ are positive as shown in Appendix B.1. Thus, imports of any harmonizing market from type $K$ countries - both within the region and in the rest of the world - and type $L$ countries with $c_{l}<\bar{g}\left(c_{k}\right)$ increase, i.e. $d Q_{i j}>0, d Q_{k j}>0, d Q_{l j}>0$ for $i, j \in H$, $k, l \notin H$.

(ii) As mentioned in Appendix B.1, the negative direct effect of $d s_{j}>0$, i.e. $n_{i j}^{*} \partial q_{i j}^{*} / \partial s_{j}$, is stronger for $i=l$. Next we consider and compare the indirect effect of $d s_{j}$, i.e. $\left(N_{j} / \gamma_{i j}\right)\left(d Q_{i j} / d n_{i j}\right) \sum_{z}\left(\partial n_{i j} / \partial n_{z j}\right)\left(\partial V_{z j}^{*} / \partial s_{j}\right)$, where $\partial n_{i j} / \partial n_{z j}$ is defined in equation (a.5) for $i=k, l$ and

$$
\begin{aligned}
\frac{\partial V_{z j}^{*}}{\partial s_{j}} & =\left(\frac{\partial P_{j}^{*}}{\partial s_{j}}-c_{z}\right) q_{z j}^{*}+\left(P_{j}^{*}-c_{i} s_{j}\right) \frac{\partial q_{z j}^{*}}{\partial s_{j}} \\
& =q_{z j}^{*}\left[\frac{\partial P_{j}^{*}}{\partial s_{j}}-c_{z}+\frac{\partial P_{j}^{*}}{\partial q_{z j}^{*}} \frac{\partial q_{z j}^{*}}{\partial s_{j}}\right] .
\end{aligned}
$$

When $c_{l}>g_{2}\left(F_{k}\right) \equiv \partial P_{j}^{*} / \partial s_{j}+\theta_{l j}-\bar{b}\left[\left(\partial P_{j}^{*} / \partial s_{j}\right)-c_{k}+\theta_{k j}\right]$ with $\theta_{z j} \equiv\left(\partial P_{j}^{*} / \partial q_{z j}^{*}\right)\left(\partial q_{z j}^{*} / \partial s_{j}\right)$ and $\bar{b} \equiv\left(q_{k j} / q_{l j}\right) \max \left\{\gamma_{k j} /\left(N_{j} \partial V_{k j}^{*} / \partial n_{l j}\right),\left(N_{j} / \gamma_{l j}\right)\left(\partial V_{l j}^{*} / \partial n_{k j}\right)\right\}$, we then obtain that $\sum_{z}\left(\partial n_{k j} / \partial n_{z j}\right)\left(\partial V_{z j} / \partial s_{j}\right)>0$ as well as $\sum_{z}\left(\partial n_{l j} / \partial n_{z j}\right)\left(\partial V_{z j} / \partial s_{j}\right)<0$. Overall, the negative net effect of $d s_{j}>0$ is stronger for $i=l$, i.e. $\psi_{l j}<\psi_{k j}<0$ where $\psi_{i j}$ is defined in Appendix B.1, which in turn suggests the positive impact of $d s_{j}<0$ is larger for $i=l$.

Now consider $\sum_{j} d Q_{i j}$ given $j \in H$, where $d Q_{i j}$ is defined in equation (a.8). Denote $\Delta \psi=\min \left\{\psi_{l j}-\psi_{k j}\right\}<0$ for $j \in H$. Then

$$
\begin{aligned}
\sum_{j} d Q_{l j}-\sum_{j} d Q_{k j} & =\sum_{j}\left(\varphi_{l j}-\varphi_{k j}\right) d N_{j}+\sum_{j}\left(\psi_{l j}-\psi_{k j}\right) d s_{j} \\
& >\sum_{j}\left(\varphi_{l j}-\varphi_{k j}\right) d N_{j}+\Delta \psi \sum_{j} d s_{j} .
\end{aligned}
$$

We find that $\sum_{j} d Q_{i j}>0$ if $\sum_{j} d s_{j}<\Delta \underline{s} \equiv-(1 / \Delta \psi) \sum_{j}\left(\varphi_{l j}-\varphi_{k j}\right) d N_{j}$. 


\section{References}

[1] Akerlof, George. (1970) "The Market for 'Lemons': Quality Uncertainty and the Market Mechanism". Quarterly Journal of Economics 84: 488-500.

[2] Baldwin, Richard. (2000) Regulatory Protectionism, Developing Nations and A TwoTier World Trade System. CEPR Discussion Paper No. 2574.

[3] Baltagi, Badi. (2001) Econometric Analysis of Panel Data, 2nd Edition. John Wiley \& Sons, Chichester, England.

[4] Frankel, J., Ernesto Stein, and Shang-Jin Wei. (1997) Regional Trading Blocs in the World Economic System. Institute for International Economics. Washington, DC.

[5] Ganslandt, Mattias, and James Markusen. (2001) "Standards and Related Regulations in International Trade: A Modeling Approach". NBER Working Paper No. w8346.

[6] Hausman, J. (1978) "Specification Tests in Econometrics". Econometrica 46: 12511271.

[7] Heckman, J. (1979) "Sample Selection Bias as a Specification Error". Econometrica 47: 153-161.

[8] Maskus, Keith E. and John S. Wilson. (2001) "A Review of Past Attempts and the New Policy Context", in Quantifying the Impact of Technical Barriers to Trade: Can it be done? edited by Keith E. Maskus and John S. Wilson. University of Michigan Press, Ann Arbor, MI.

[9] Moenius, Johannes. (2000) Three Essays on Trade Barriers and Trade Volumes. Ph.D. Dissertation. University of California, San Diego.

[10] Mundlak, Yair. (1978) "On The Pooling of Time Series and Cross-Section Data". Econometrica 46: 69-85. 
[11] Soloaga, Isidro, and L. Alan Winters. (2001) "Regionalism in the Nineties: What Effect on Trade?" CEPR Discussion Paper 2183. Center for Economic Policy Research, London.

[12] Swann, Peter, Paul Temple, and Mark Shurmer. (1996) "Standards and Trade Performance: The UK Experience". Economic Journal 106: 1297-1313.

[13] European Commission. (1998) Single Market Review. Subseries III: Dismantling of Barriers. Volume 1: Technical Barriers to Trade.

[14] World Bank. (2004) Technical Barriers to Trade Database: Washington, DC.

[15] Vella, Francis. (1993) "A Simple Estimator for Simultaneous Models with Censored Endogenous Regressors". International Economic Review 34: 441-457.

[16] Vogel, David. (1995) Trading Up: Consumer and Environmental Regulation in A Global Economy. Harvard University Press, Cambridge, Massachusetts. 